\title{
AMOR E ÓDIO: VIOLÊNCIA DOMÉSTICA - a vivência do psiquiatra $^{61}$
}

\section{Mariana Rangel Maciel62}

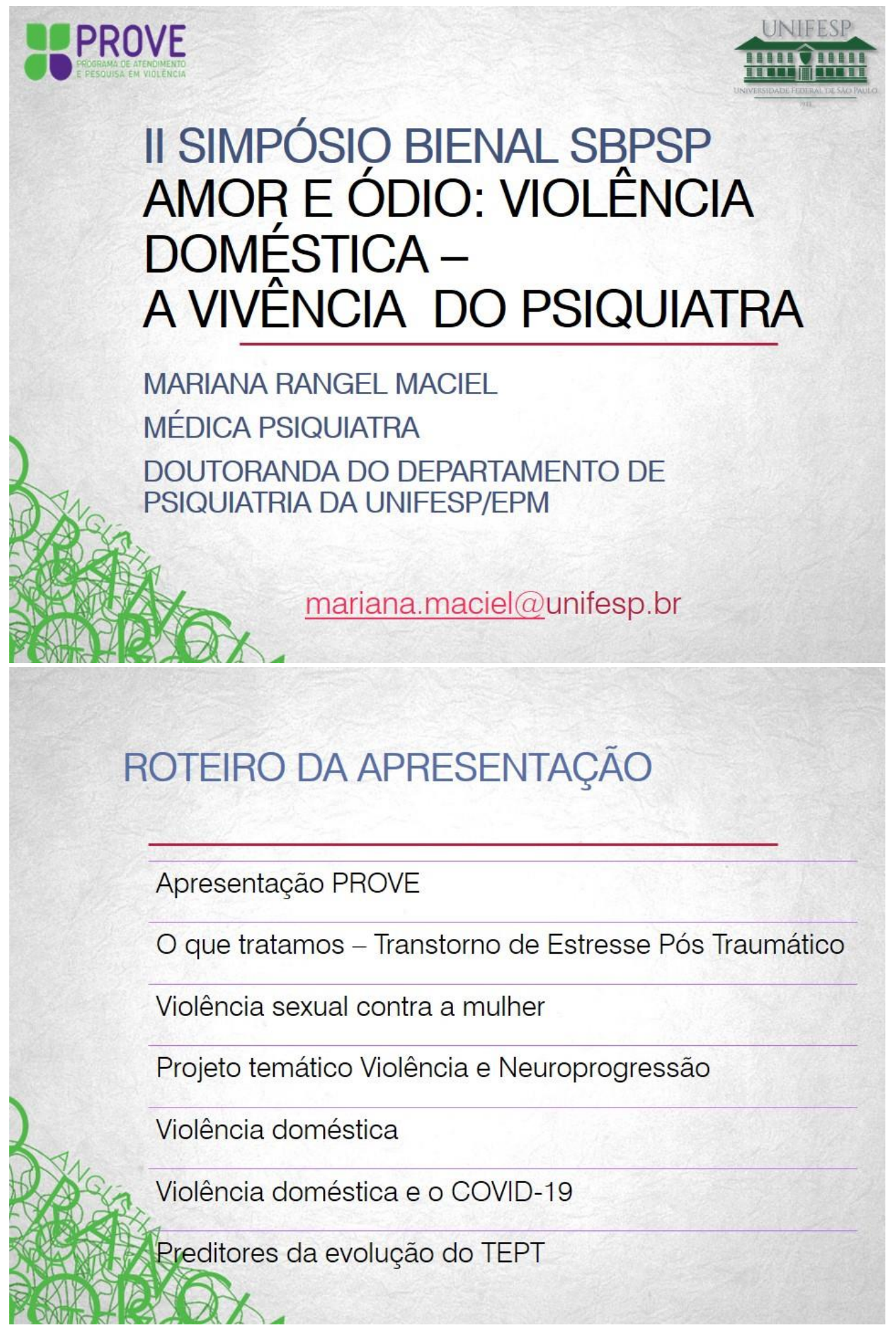

${ }^{61}$ Trabalho apresentado na mesa "Amor e ódio: violência doméstica” no II Simpósio Bienal SBPSP "Fronteiras da Psicanálise: a clínica em movimento" no dia 22 de agosto de 2020.

62 Psiquiatra do Serviço de Assistência e Pesquisa em Violência e Estresse Pós Traumático, Mestre e doutoranda em Ciências pela UNIFESP, membro da ISIPT. 

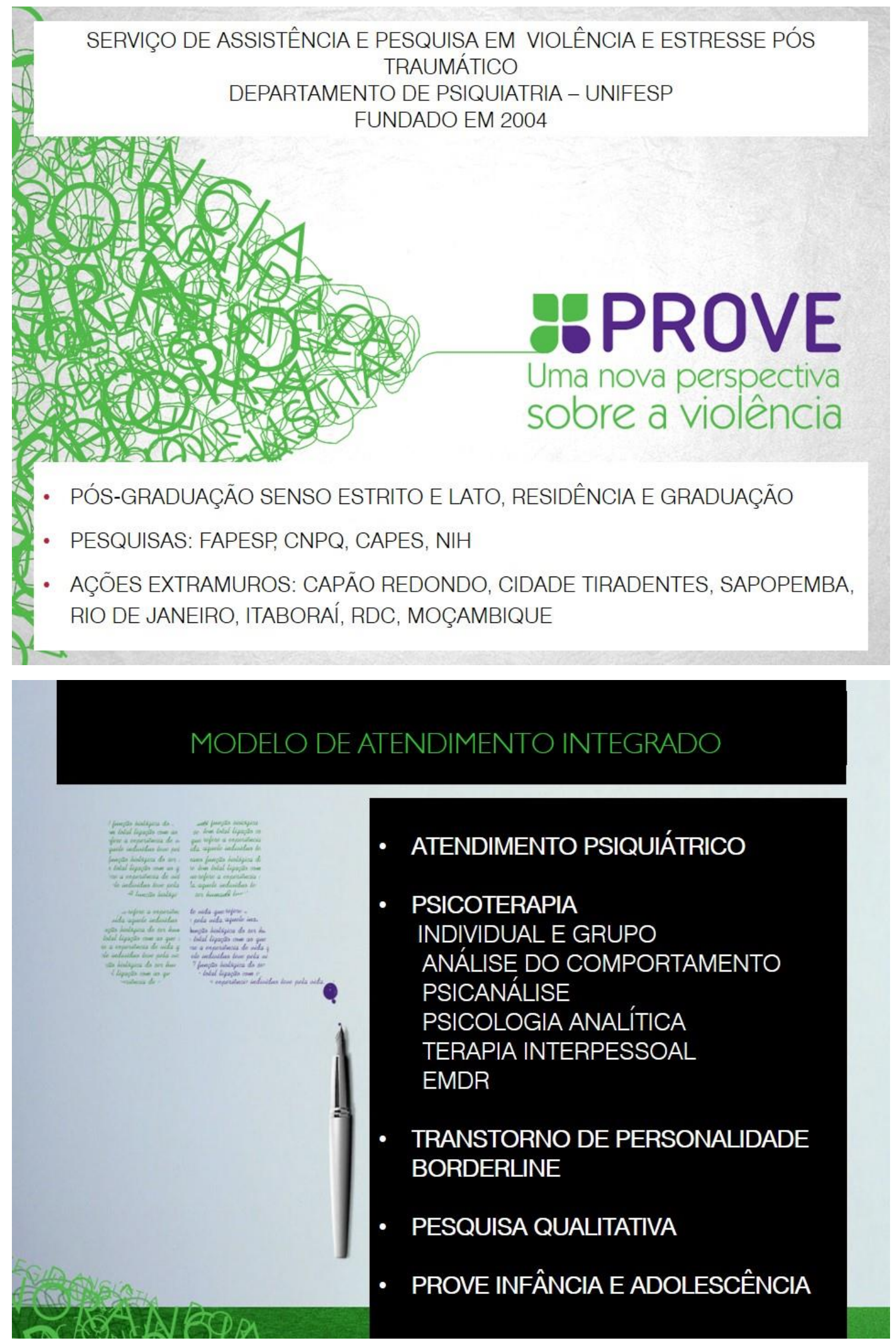


\section{TRATAMENTO ESPECÍFICO PARA O TRANSTORNO DE ESTRESSE PÓS TRAUMÁTICO (TEPT), SEGUNDO OS CRITÉRIOS DO DSM-5}

- Transtornos relacionados a trauma e estresse

- Eventos que ameaçam a integridade do indivíduo

- 4 grupos de sintomas

B. Intrusivos (1)

C. Evitação (1)

D. Alterações negativas na cognição e no humor (2)

E. Hipervigilância e hiperreatividade (2)

DSM-5, American Psychiatric Association, 2014

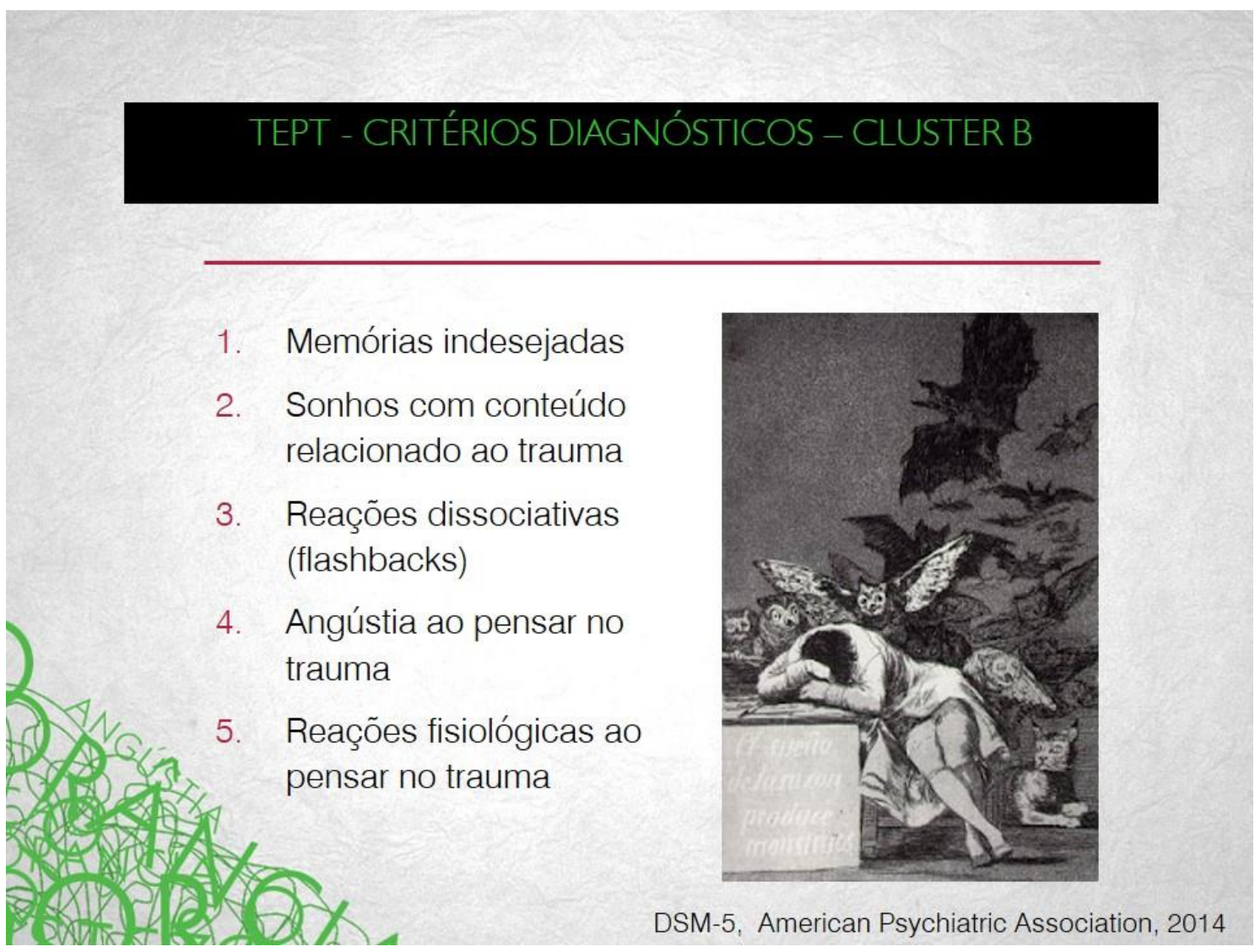




\section{TEPT - CRITÉRIOS DIAGNÓSTICOS CLUSTER C}

- Evitação de sentimentos e pensamentos (gatilhos internos)

- Evitação de lugares, situações, pessoas (gatilhos externos)

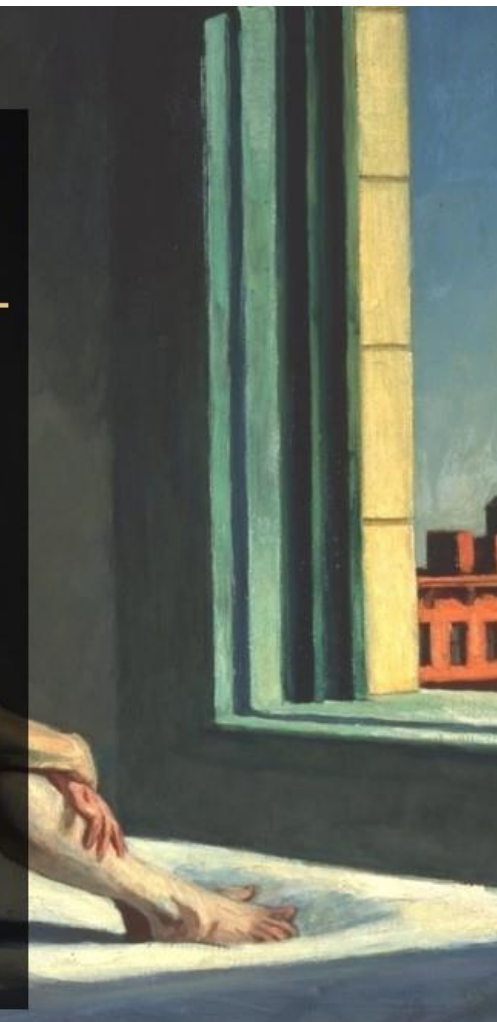

DSM-5, American Psychiatric Association, 2014

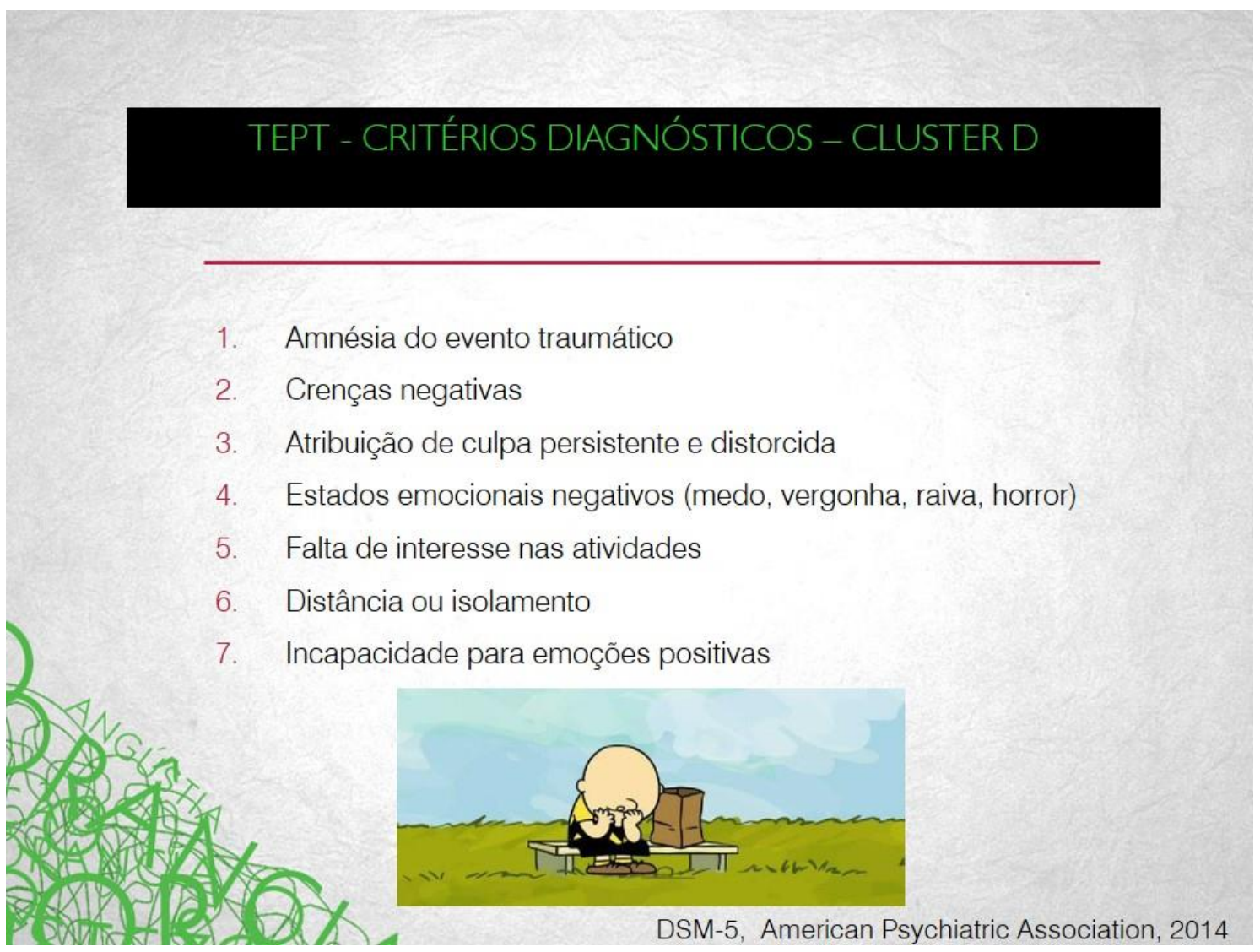




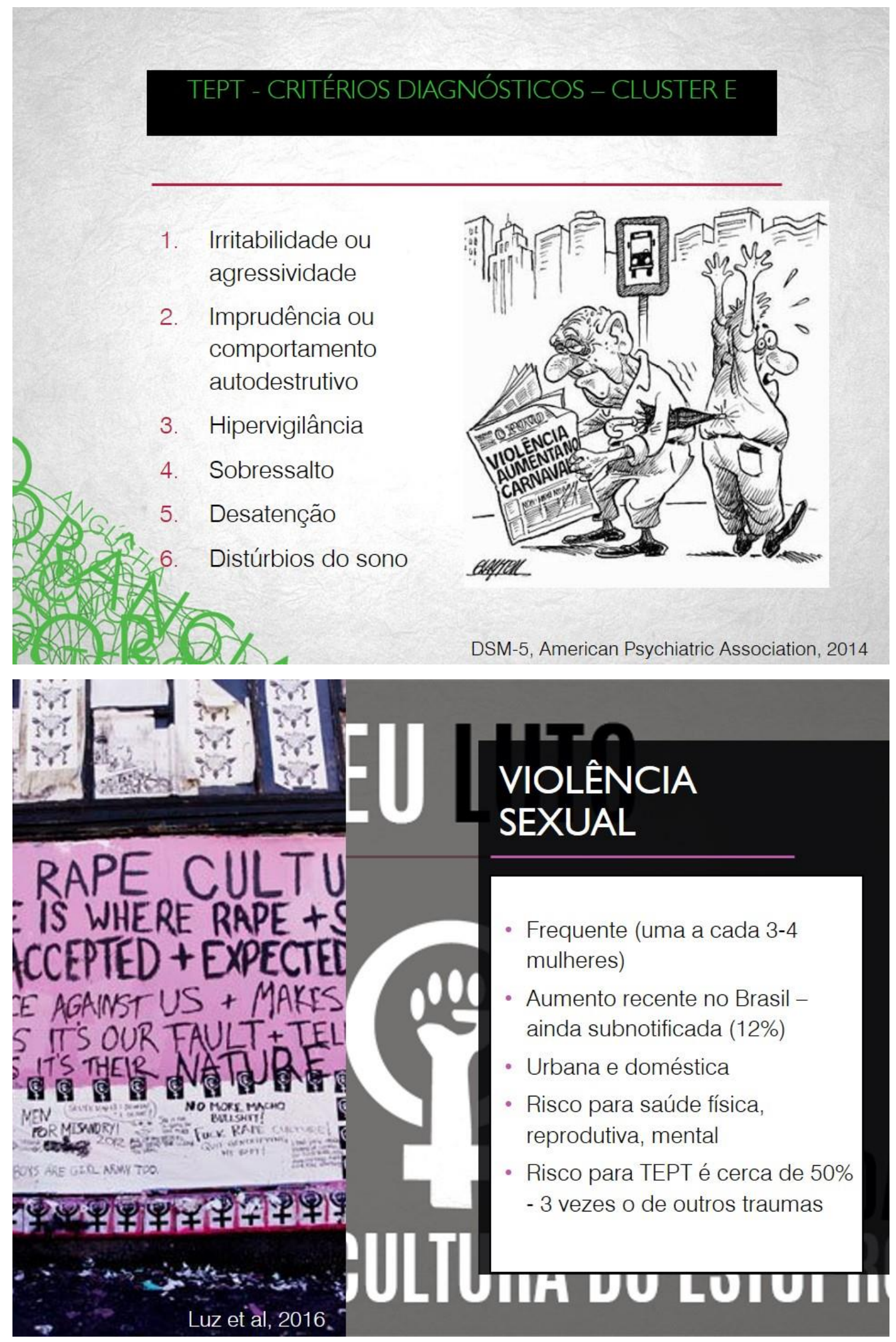




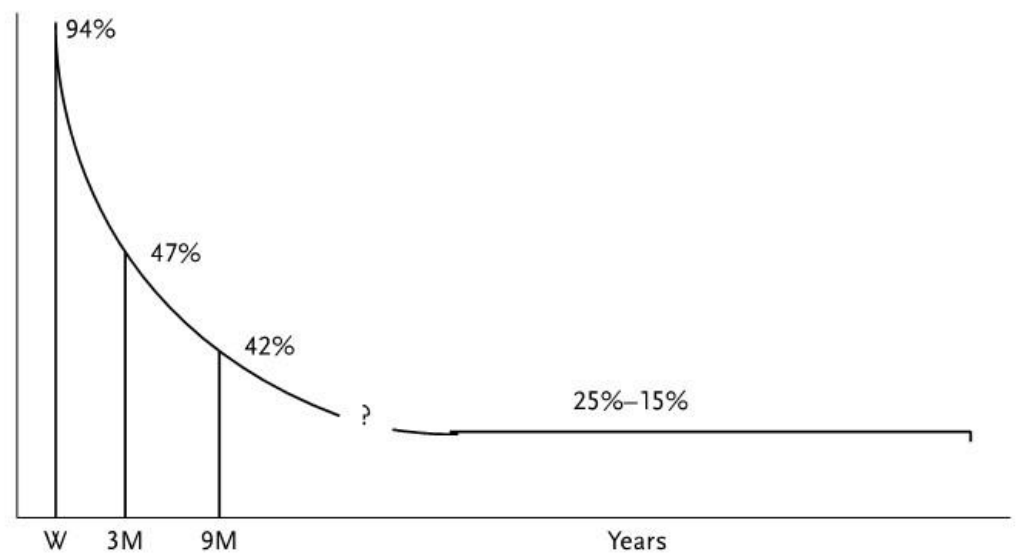

Figure 11.2 Longitudinal course of post-traumatic stress disorder (PTSD) rates after trauma among rape victims. Adapted from Rothbaum, B. O., Foa, E. B., Riggs, D. S., Murdock, T., \& Walsh, W. (1992). A prospective examination of post-traumatic stress disorder in rape victims. Journal of Trauma and Stress, 5(3), 455-475.

\section{TRANSTORNO DE ESTRESSE PÓS-TRAUMÁTICO E NEUROPROGRESSÃO}

TRAUMA E ESTRESSE NO AUMENTO DA CARGA ALOSTÁTICA E ACELERAÇÃO DO PROCESSO DE ENVELHECIMENTO PRINCIPAL INVESTIGADOR: MARCELO FEIJÓ DE MELLO PROJETO TEMÁTICO FAPESP 2014/12559-5 VIGENCIA: 01/05/2015 A 30/04/2021

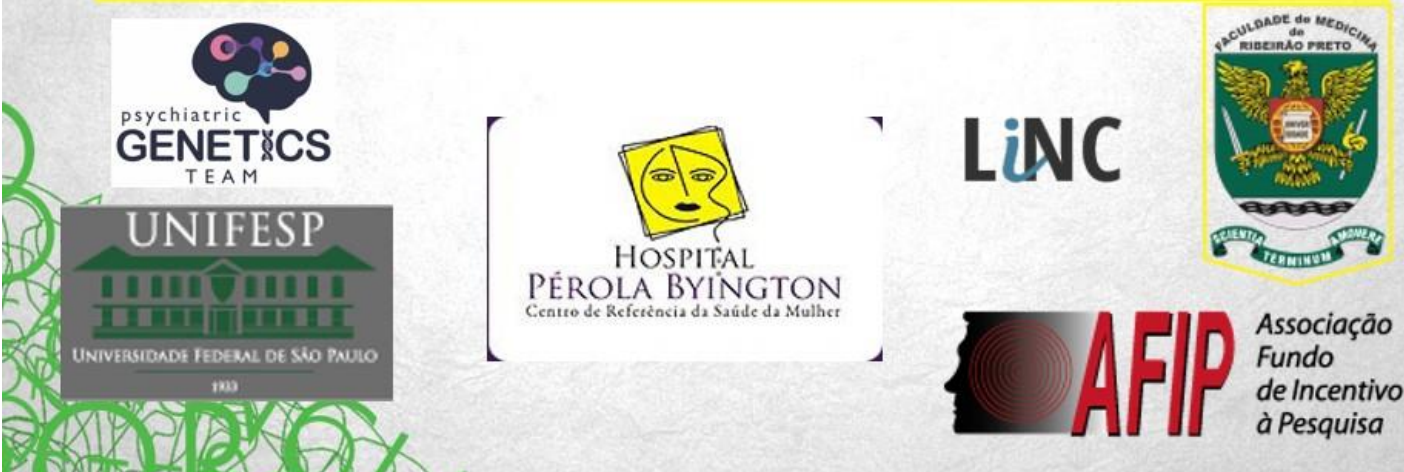




\section{FLUXOGRAMA}

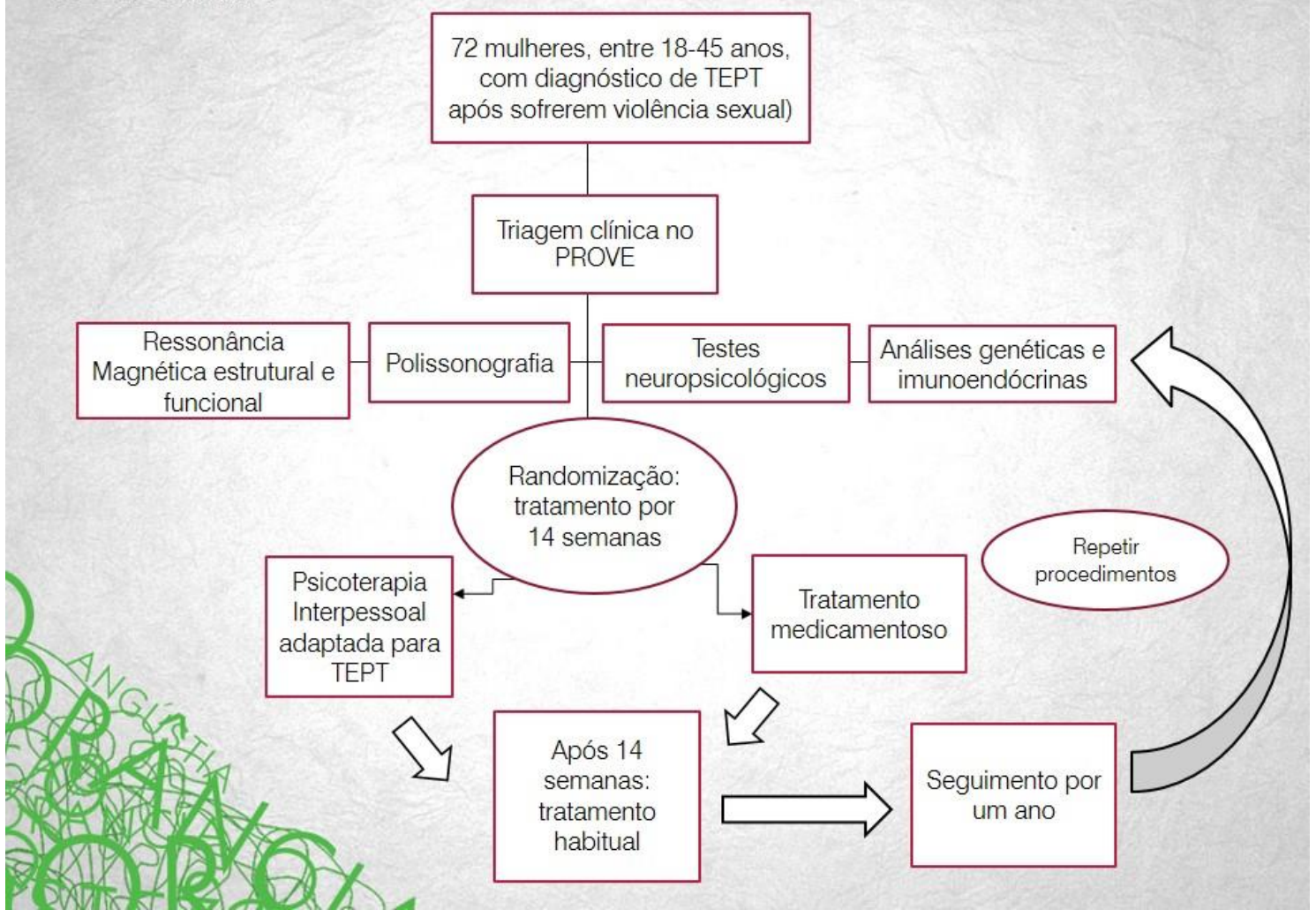

\section{ALGUNS RESULTADOS}

- Houve efeito cumulativo de carga traumática ao longo da vida

- Nível socioeconômico mais baixo relacionou-se à maior gravidade dos sintomas de TEPT no momento de entrada no estudo

- Os dois grupos melhoraram de forma semelhante

- Casos de violência eram quase na totalidade violência urbana - viés de seleção 

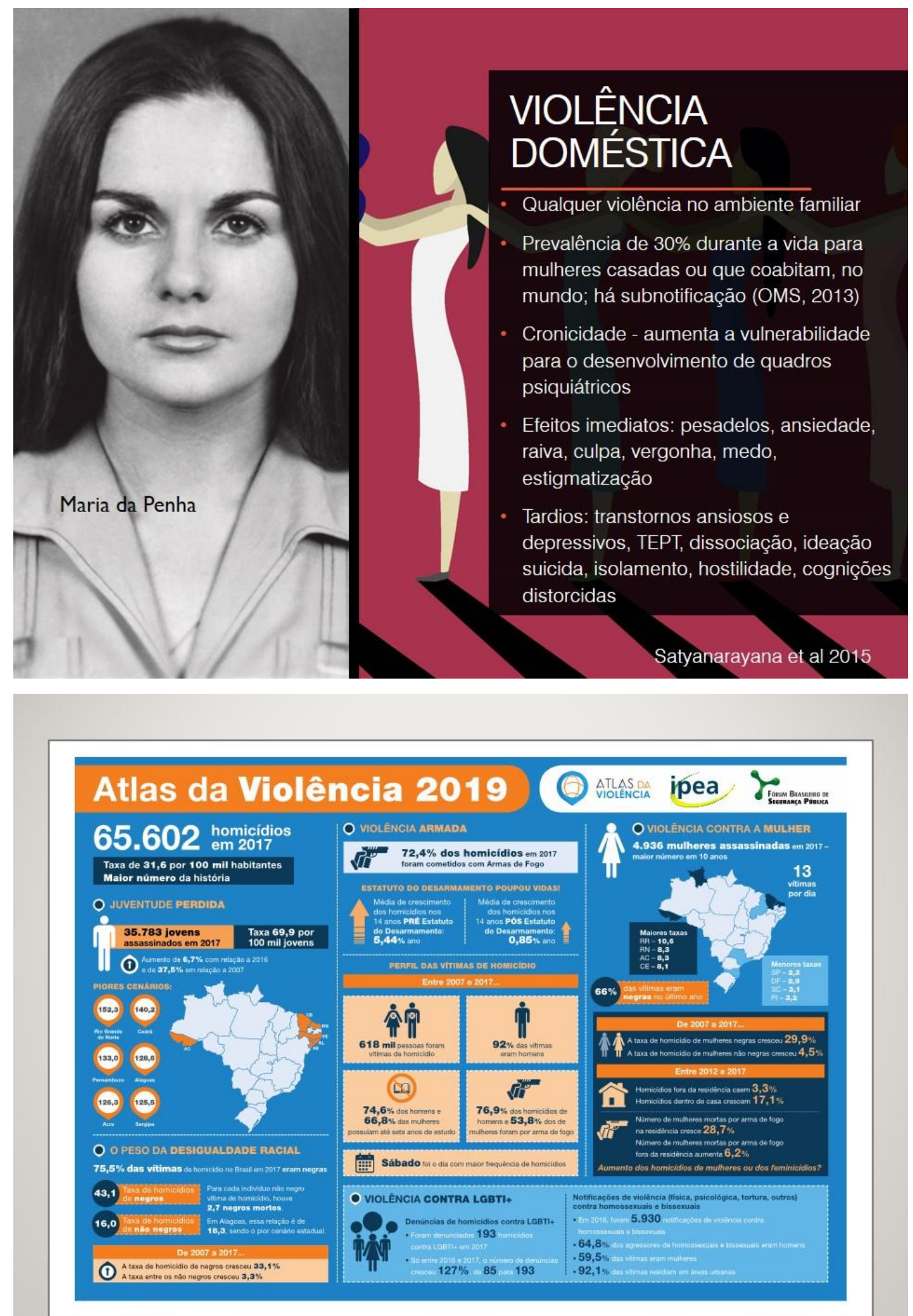
I ndices de base 100 da evolução das taxas de homićdio de mulheres dentro e fora da residência e ainda por arma de fogo (2012-2017)

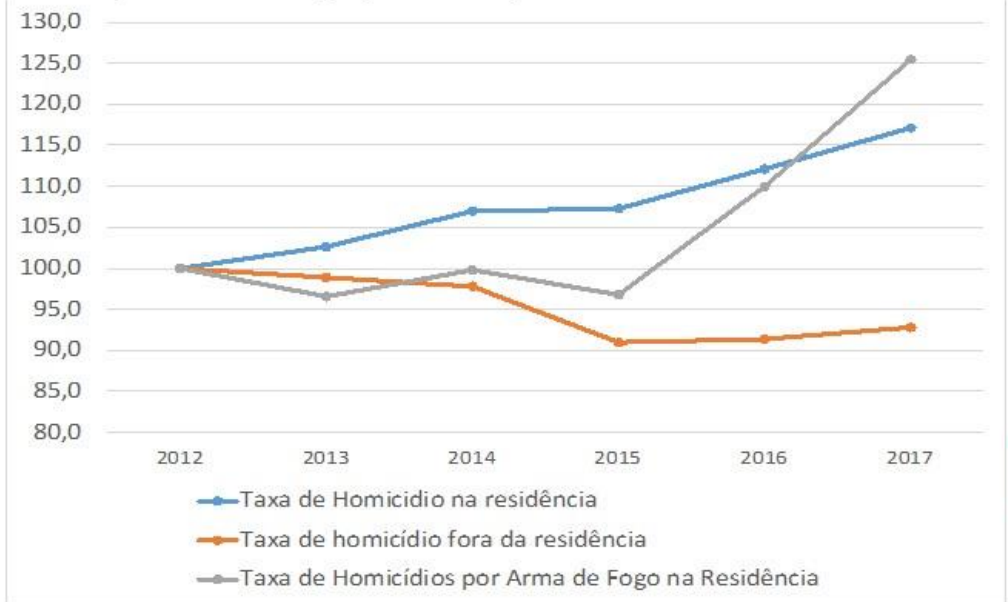
Demográfica e MS/SVS/CGIAE - Sistema de Informações sobre Mortalidade - SIM. El abor ação Diest/Ipea e FBSP.

\section{VISIVEL E INVISIVEL:}

\section{A VITIMIZAÇÃO DE} MULHERES NO BRASIL

- Com o aumento da faixa etária, o local de violência migra da rua para a casa

- Fica também mais comum que o agressor seja uma pessoa conhecida da vítima

\section{MARÇO 2017}

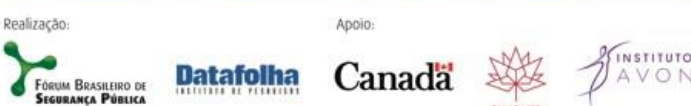

- Alta renda: locais mais comuns foram casa $(52 \%)$ e trabalho $(23 \%)$

- Baixa renda: maior equilíbrio (43\% casa e $44 \%$ rua)

- Padrão semelhante em relação à raça 
THE INTERPRETER

\section{ANew Covid-19 Crisis: Domestic Abuse Rises Worldwide}

Movement restrictions aimed to stop the spread of the

coronavirus may be making violence in homes more frequent, more severe and more dangerous.
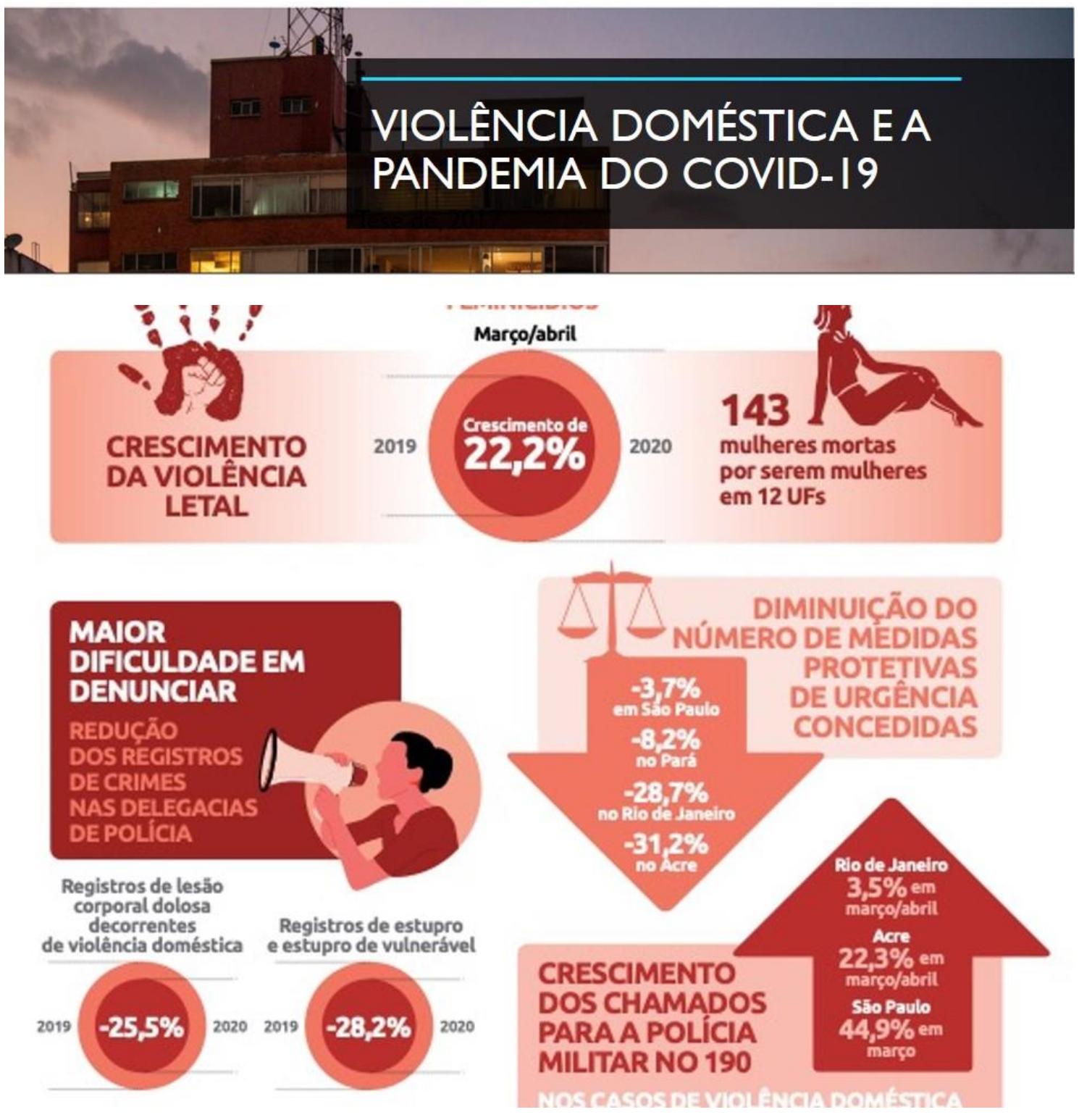


\section{FATORES AGRAVANTES DURANTE A PANDEMIA}

- Sobrepõem-se à estrutura patricarcal / desigualdade de gênero / cultura machista:

- Isolamento social

- Impacto econômico

- Sobrecarga do trabalho doméstico e cuidados com os filhos

- Impacto emocional da pandemia / estresse

- Abuso de álcool e outras drogas

- Redução do alcance dos serviços de enfrentamento e suporte

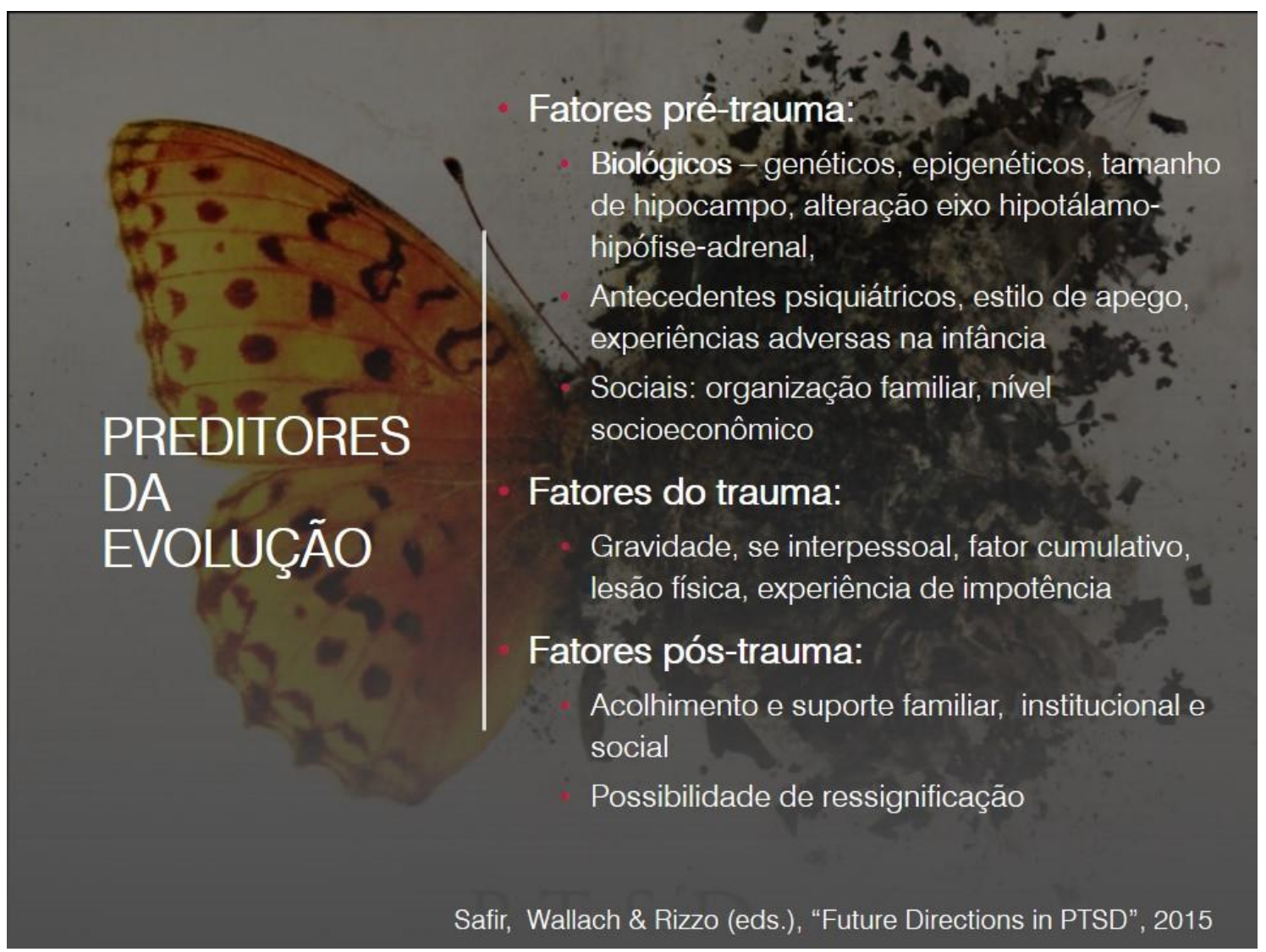




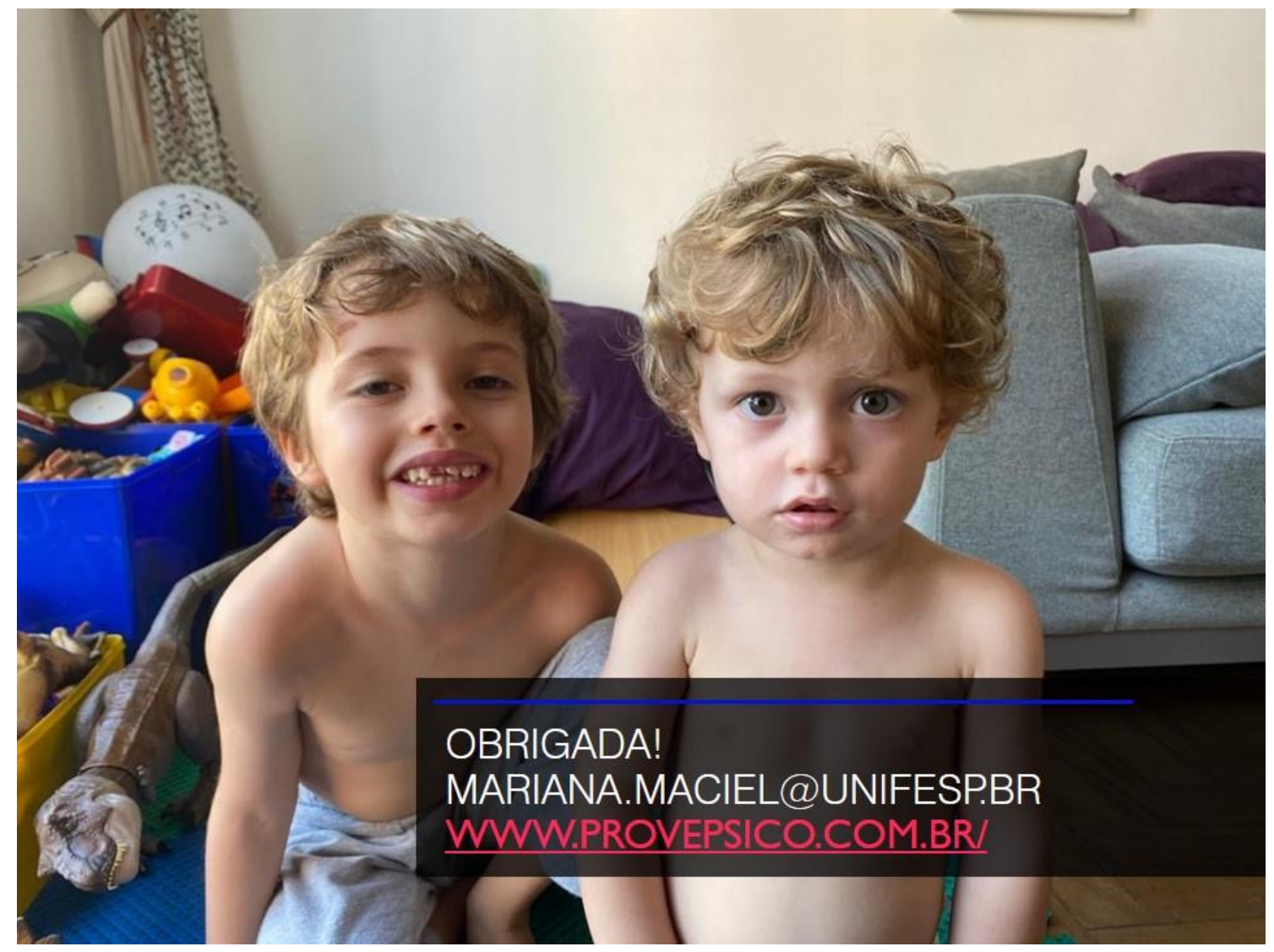

